Article

\title{
New Insights into the Structure of Glycols and Derivatives: A Comparative X-Ray Diffraction, Raman and Molecular Dynamics Study of Ethane-1,2-Diol, 2-Methoxyethan-1-ol and 1,2-Dimethoxy Ethane
}

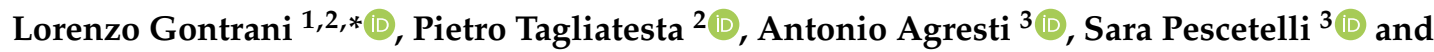 \\ Marilena Carbone ${ }^{2, *(D)}$ \\ 1 Department of Chemistry, University of Rome La Sapienza, P. le A. Moro, 00185 Roma, Italy \\ 2 Department of Chemical Science and Technologies, University of Rome, Tor Vergata, Via della Ricerca \\ Scientifica-1, 00133 Roma, Italy; pietro.tagliatesta@uniroma2.it \\ 3 Department of Electronic Engineering, University of Rome Tor Vergata, Via del Politecnico 1, 00133 Roma, \\ Italy; antonio.agresti@uniroma2.it (A.A.); pescetel@uniroma2.it (S.P.) \\ * Correspondence: lorenzo.gontrani@uniroma2.it (L.G.); carbone@uniroma2.it (M.C.)
}

Received: 2 October 2020; Accepted: 3 November 2020; Published: 6 November 2020

\begin{abstract}
In this study, we report a detailed experimental and theoretical investigation of three glycol derivatives, namely ethane-1,2-diol, 2-methoxyethan-1-ol and 1,2-dimethoxy ethane. For the first time, the X-ray spectra of the latter two liquids was measured at room temperature, and they were compared with the newly measured spectrum of ethane-1,2-diol. The experimental diffraction patterns were interpreted very satisfactorily with molecular dynamics calculations, and suggest that in liquid ethane-1,2-diol most molecules are found in gauche conformation, with intramolecular hydrogen bonds between the two hydroxyl groups. Intramolecular H-bonds are established in the mono-alkylated diol, but the interaction is weaker. The EDXD study also evidences strong intermolecular hydrogen-bond interactions, with short $\mathrm{O} \cdots \mathrm{O}$ correlations in both systems, while longer methyl-methyl interactions are found in 1,2-dimethoxy ethane. X-ray studies are complemented by micro Raman investigations at room temperature and at $80{ }^{\circ} \mathrm{C}$, that confirm the conformational analysis predicted by $\mathrm{X}$-ray experiments and simulations.
\end{abstract}

Keywords: ethane-diols; methoxy and dimethoxy ethane; liquid structure; hydrogen bond; XRD; Raman

\section{Introduction}

Ethylene glycol (ethane-1,2-diol; EG) and its mono-alkyl ether derivative 2-methoxyethan-1-ol (ME, also known as methylcellosolve) have many applications in several fields. EG is used in engineering and biology, acting as a coolant, an antifreeze, an anti-icing agent in gas pipelines, de-icing solutions for vehicles and runways of airports and a cryo-protectant, in addition to finding widespread application in the synthesis of many polymers [1] and pharmaceuticals [2]. Amongst other uses, it serves as an ingredient of electrolytic capacitors, printer's inks, and it is used as a solvent. It is raw material for the production of explosives and synthetic waxes [3]. Cellosolves are used as industrial and biological solvents, surfactants, detergents and wetting agents. Such solvents are also used as a media with variable viscosity in experimental studies of the solvent dynamics effect on electrochemical reactions $[4,5]$. Renewed interest in EG was recently found in the field of solvents for green and sustainable chemistry, where it was reported that EG can be used as a hydrogen bond donor to form 
deep eutectic solvents (DES) with significantly lower viscosities than most "traditional" DES [6]. Indeed, this small molecule has very large hydrogen bond capabilities, owing to the presence of two hydroxyl moieties, which can act as both hydrogen bond donors and acceptors groups, in a quite limited space with little interference from the hydrophobic interactions between the small alkyl chains. This property allows EG (and, to a lesser extent, DME) to form quite extended and highly correlated 2D and 3D networks that are responsible for most of their properties. However, the presence of an alkyl chain, though very short, plays a major role, since the molecule can adopt partially folded conformations in which the two $\mathrm{OH}$ groups can interact to give intramolecular hydrogen bonds, with consequent kinks of the network. The complexity of the matter has promoted several theoretical and experimental studies so far. Many computational studies have been done, at various levels of theory, in order to understand the relative thermodynamic stability of the EG molecule's conformations and to assess the role of intra- and inter-molecular hydrogen bonding, both in EG and in EG-water [7-9]. These investigations suggest that the liquid structure is dominated by a hydrogen-bonded network with a mean number of hydrogen bonds per molecule slightly lower than four, independently of the potential model used. The structure of the isolated ethylene glycol molecule has been studied experimentally by electron diffraction [10] as well as by microwave [11] and infrared spectroscopic methods in the gas phase/low-temperature matrix [12,13], whereas the strong structural correlations of condensed-phase EG were investigated by diffraction techniques (X-ray and neutron [14]) in the liquid, focusing in particular on the structure of the most stable dimers, and in the solid state by neutron diffraction [15]. As far as the liquid structure is concerned, infrared and Raman spectra suggest that almost all $\mathrm{OH}$ groups are involved in inter-and intramolecular $\mathrm{H}$-bonds [16,17].

Studies on cellosolves structures are less abundant, and mostly focused on the characterization of heterogeneous interactions between the polar molecules in their binary mixtures [18] or their toxicity [19]. Here we present a comparative energy dispersive X-ray diffraction, Raman and molecular dynamics study of EG, 2-methoxyethan-1-ol (ME) and 1,2-dimethoxyethane (DME) in the pure liquid phase. The aim is at shedding light on the inter and intra molecular hydrogen bond networks and majority conformations in these pure liquids, combining two techniques capable of yielding structural information with a simulation protocol that helps in interpreting diffraction patterns. In order to obtain a complete picture, DME was also investigated, since it cannot form hydrogen bonds; hence, it can provide a negative control. To our knowledge, this is the first report on ME and DME structure by X-ray diffraction.

\section{Materials and Methods}

Ethane-1,2-diol, 2-methoxyethan-1-ol, 1,2-dimethoxyethane were purchased from Sigma-Aldrich (Milano, Italy) and used as received.

Energy dispersive X-ray dispersion (EDXD) measurements of the liquid samples were performed using a noncommercial energy scanning diffractometer (built in house) [20]. The EDXD technique is a variant of X-ray diffraction that exploits the dependence of diffracted intensity on the energy of the radiation, according to the definition of the scattering variable for the Compton scattering between a photon and an electron:

$$
\mathrm{q}=\frac{4 \pi \sin (\theta)}{\lambda}
$$

This relation links the magnitude of the scattering variable (or momentum transfer) to the scattering angle $(2 \theta)$ and to the wavelength of the incident radiation. Since the wavelength is related to the energy of the photon by the Planck equation $\mathrm{E}=\mathrm{h} v(\mathrm{~h}=$ Planck constant), we obtain:

$$
\mathrm{q}=\frac{4 \pi \sin (\theta)}{\mathrm{hc}} \mathrm{E} \approx 1.014 \mathrm{E} \sin (\theta)
$$

Therefore, the whole spectrum of scattered wavevectors can be obtained either by varying the angle and keeping the radiation energy fixed (angular dispersive, ADXD, that uses a monochromatized 
beam) or by using a variable-wavelength energy beam (i.e., the "white" part of the radiation emitted by an X-ray tube-Bremsstrahlung) and using a single angle, or a limited number of angles (in this case $\mathrm{q}=24.0^{\circ}, 8.0^{\circ}, 3.0^{\circ}, 1.0^{\circ}, 0.5^{\circ}$ ). The scattered intensity obtained at each angle undergoes a data treatment procedure, that normalizes the measured scattered intensity for absorption and subtracts self-scattering and the inelastic Compton incoherent scattering, yielding the total coherent structure factor, which is also known as "reduced intensity", I(q):

$$
I(q)=(q)-\sum_{x=1}^{N} x_{i} f_{i}^{2}-I_{\text {incoh }}
$$

$\mathrm{I}(\mathrm{q})$ is the structural sensitive part of the recorded diffracted intensity $\mathrm{I}_{\exp }$, as it depends on the sum of the interference contributions of the waves scattered by the atoms of the sample, and, ultimately, on their relative distances, as the atoms, through their electrons, are the particles taking part to the scattering phenomenon (scatterers). The structure factors obtained from the different measurements (i.e., the 3-4 different angles) are finally joined to obtain a continuous spectrum in $q$, which in this study ranged from 0.5 to $24 \AA^{-1}$.

Several papers on EDXD theory $[20,21]$ and applications [22-25], to which the reader is referred to, were published in the past. From the Fourier transform of $\mathrm{I}(\mathrm{q})$, the total radial distribution function of the sample is obtained. This is a "real" space (or "direct" space) representation of the scattering, and is complementary to the $\mathrm{I}(\mathrm{q})$, as the same structural features may give a strong signature in $\mathrm{I}(\mathrm{q})$ and a small one in the radial distribution, and vice versa. It is important to note that the radial distribution is a function of the (relative) distance, while the "reciprocal" space I(q) depends on momenta, that are inversely proportional to the distance (large distance $=$ small momentum and vice versa). The functional form chosen for the total radial distribution functions shown in this work is the "differential" one (Diff (r)), defined as:

$$
\mathrm{D}(\mathrm{r})-4 \pi \rho_{0}=\operatorname{Diff}(\mathrm{r})-\frac{2 \mathrm{r}}{\pi} \int_{0}^{\infty} \mathrm{qI}(\mathrm{q}) \mathrm{M}(\mathrm{q}) \mathrm{rsin}(\mathrm{q}) \mathrm{dq}
$$

In this expression, the non-structural term, due to the uniform radial distribution of particles that depends on the system density $\rho_{0}$, is left out. $\mathrm{M}(\mathrm{q})$ is a mathematical function used to reduce the truncation error of the Fourier transform and to highlight the large q contributions, and is equal to:

$$
\mathrm{M}(\mathrm{q})=\frac{\mathrm{f}_{\mathrm{N}}^{2}(0)}{\mathrm{f}_{\mathrm{N}}^{2}(\mathrm{q})} \exp \left(-0.01 \mathrm{q}^{2}\right)
$$

The function $\mathrm{I}(\mathrm{q})$ is related to the partial radial distribution functions descriptive of the structure and obtainable from the simulations, according to:

$$
I(q)=\sum_{i=1}^{N} \sum_{j=1}^{N} x_{i} x_{i} f_{i} f_{j} 4 \pi \rho_{0} \int_{0}^{\infty} r^{2}\left(g_{i j}(r)-1\right) \frac{\sin (q r)}{q r} d r
$$

In the equation above, $x_{i}$ and $x_{j}$ are the numerical concentrations of the species while fi and $f_{j}$ are their q-dependent $X$-ray scattering factors and $\rho_{0}$ is the bulk number density. This relation is the link between experimental and model data, as the $\mathrm{g}(\mathrm{r}) \mathrm{s}$ can be calculated from molecular simulations. Comprehensive derivation of all the equations is described elsewhere [26].

Considering that the molecules considered in this study also differ for short range correlations (i.e., molecular conformations and intra-molecular hydrogen bonding), we decided to use the "sharpened" version of the structure factor, $\mathrm{q}(\mathrm{q}) \mathrm{M}(\mathrm{q})$, that highlights such differences at large $\mathrm{q}$ and when comparing model and experimental data, instead of the $S(\mathrm{q})$ function that is less detailed at large $\mathrm{q}$. 
Summarizing, the analysis of both reciprocal space (q I(q) M(q)) and distance space (Diff (r)) functions is used to compare X-ray experimental data and simulations. This methodology has been successfully applied to the study of molecular [27-29], ionic liquids [30,31], deep eutectic solvents [32] as well as solutions [33-36].

Raman spectroscopy was conducted through Jobin-Yvon-Horiba micro-Raman system (LabRAM ARAMIS) equipped with $\mathrm{Ar}+$ ion laser $(514 \mathrm{~nm} / 488 \mathrm{~nm})$ as excitation source $(100 \mathrm{~mW})$ [37]. The Horiba micro-spectrometer (HORIBA, 2 Miyanohigashi, Kisshoin, Minami-ku Kyoto 601-8510, Japan) is coupled with a confocal microscope that allows the spatial resolution of the sample through detector pinhole aperture. The cut-off from the notch filters in the spectrometer is less than $120 \mathrm{~cm}^{-1}$. The spectrometer is equipped with a diffraction grating of 1800 lines $/ \mathrm{mm}$ coupled to a CCD camera. The laser light reached the sample surface at normal incidence by means of ultra-long working distance $(50 \times)$ objective with $10.5 \mathrm{~mm}$ focal distance. The scattered radiation was collected in a backscattering geometry. Subtraction of the fluorescence background on the Raman spectra was performed by a polynomial fitting, while spectral deconvolution was carried out by nonlinear least-squares fitting of the Raman peaks to a mixture of Lorentzian and Gaussian line shapes, providing the peak position, width, height, and integrated intensity of each Raman band [38]. The laser spot has a diameter of approximately $2.5 \mu \mathrm{m}$ and a power density of $0.25 \mathrm{~mW} / \mu \mathrm{m}^{2}$ with an optical density filter of 0.6 . This amount of power is necessary to avoid damage to the samples and minimize any spectrum fluctuation due to heat induced by the laser [39].

The classical molecular dynamics studies were developed using the PMEMD program package (part of the AMBER [40] suite of programs, University of California, San Francisco (USA)) as molecular dynamics engine using the GAFF force field [41] to describe the system energetics. The cubic simulation cells were prepared using the software Packmol [42] and contained 1000 molecules each, corresponding to $10,000,13,000$ and 16,000 atoms; the initial cell edges were chosen as twice the distance of the last visible peak in experimental radial distribution function (Diff (r)), i.e., $50 \AA$, considering that periodic boundary conditions apply in the simulation. The system was first minimized to relieve bad contacts and was then heated and equilibrated at $300 \mathrm{~K}$ in the NPT ensemble for $5 \mathrm{~ns}$. The edges of the equilibrated cells were: 44.80, 50.90 and 55.08 ̊, for ETG, ME and DME, respectively, with 1.15, 0.96 and $0.88 \mathrm{~g} \mathrm{~cm}^{-3}$ as corresponding theoretical density values, that compare very nicely with experimental ones (1.11, 0.97 and $0.87 \mathrm{~g} \mathrm{~cm}^{-3}$ ), with only a slightly larger deviation for ETG (3.6\%). This observation constituted the first proof of the validity of the simulation protocol. A production trajectory lasting another $5 \mathrm{~ns}$ was finally obtained in the NVT ensemble with the system density fixed at the experimental values. The calculation of structure factors and radial distribution functions was made on 2000 frames of this trajectory (one over $2.5 \mathrm{ps}$ ) using in-house codes and the TRAVIS software [43].

\section{Results and Discussion}

\subsection{X-Ray Structural Study}

The structure factors for the three systems investigated are shown in Figure 1 upper panel). All the liquids share overall similar patterns, though some important differences can be pointed out:

- In the $2-3.5 \AA^{-1}$ range, that correspond to an effective distance range (estimated as $d \approx 2 \pi / \mathrm{q}$ ) between 1.8 and $3.2 \AA$, and is the part of reciprocal space data most sensitive to short intermolecular correlations, like hydrogen bonding, a clear decrease of the peak intensity is observed going from EG to ME, while in DME the peak partly recovers the intensity, but is shifted at larger q.

- The faint peak round $10 \AA^{-1}$ in EG is progressively split into two peaks by OH substitution.

The qualitative analysis of the radial distributions, plotted in Figure 1 (lower panel), confirms that EG has sizable correlations in the distance range 2.5-4 $\AA$, that get smaller in ME and disappear in DME, apart from the shoulder around 3.8 $\AA$. Noteworthy is the larger extension of intermolecular interactions for the system with maximum number of hydrogen bond donor/acceptors (ethylene glycol, EG) compared to the other two liquids. Four solvation shells can be identified, at 5, 9, 13 and $17 \AA$ 
respectively, while the structural correlations of the other two liquids fades out into the continuum at larger lengths.
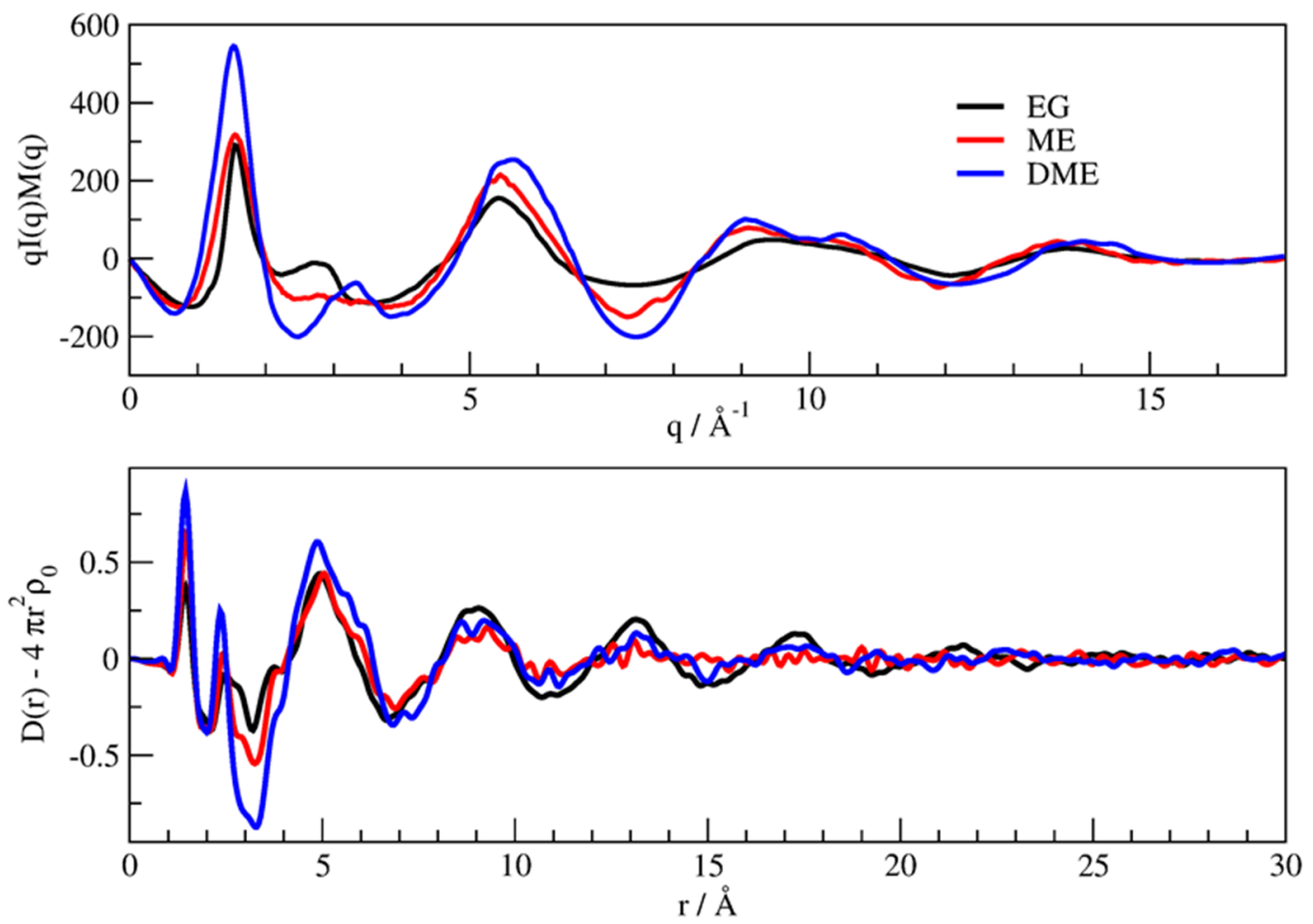

Figure 1. X-ray structure factors (top panel) and total radial distribution functions (bottom panel) of the liquids. Ethylene glycol (EG): black; methylcellosolve (ME): red; 1,2-dimethoxyethane (DME): blue.

As regards the comparison between model and experimental structure factors, reported in Figure 2, the agreement between simulated and measured data is very satisfactory for each system, only DME curve is a little out of phase at large q, possibly indicating slightly too long distances in the model. The agreement observed makes us confident about the validity of the model and allows us to perform further analyses on the calculated trajectory to obtain a series of structural properties of the liquids. To begin, we calculated the intramolecular and intermolecular radial distribution functions between hydroxyl groups of the three liquids, followed by the intramolecular radial distribution function between hydroxyl and methoxy groups (ME) and the two methoxy groups (DME); the two patterns are shown in Figure 3, right and left panel, respectively; the atom numbering is reported in the sketches of Figure 4. The conformation of EG molecules in the gas, liquid and solid glasses has been largely investigated [44-48] and it was pointed out the existence of the gauche conformer in the solid and gas phases while an equilibrium of gauche and anti conformers is established in the liquid phase. Actually, it is widely accepted that all EG molecules are mostly gauche conformers in the vapor, because this form is stabilized by intramolecular hydrogen bonds. On the other hand, in the liquid phase, the presence of $\mathrm{OH}$ groups in EG and ME suggests the possible establishment of hydrogen bonds between the molecules.

These bonds are generally found to be stronger than intramolecular bonding because steric hindrance leads to interactions with less linearity in the latter case [49]. This issue was extensively studied by Schwartz [47], who proposed two possible molecular configurations in the bulk liquid:

1. A cyclic dimer (with both EG molecules in the gauche conformation) containing two intermolecular bonds connecting the monomers, added to four additional hydrogen bonds with other molecules;

2. A molecule in the anti configuration, capable of participation in as many as four hydrogen bonds with neighboring molecules. 


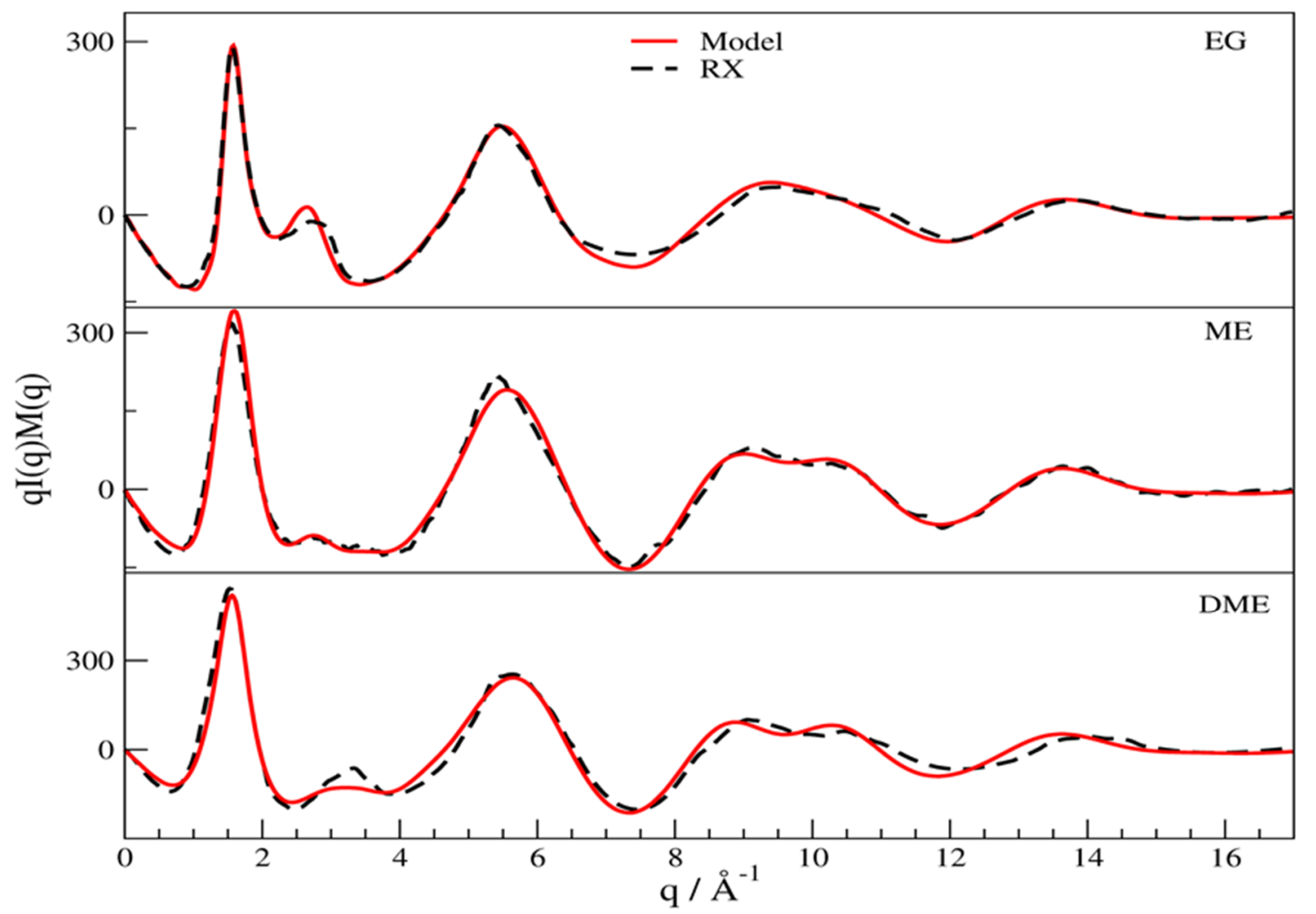

Figure 2. Measured (black dash) and simulated (red line) X-ray structure factors. EG: top panel, ME: middle panel; DME: bottom panel.

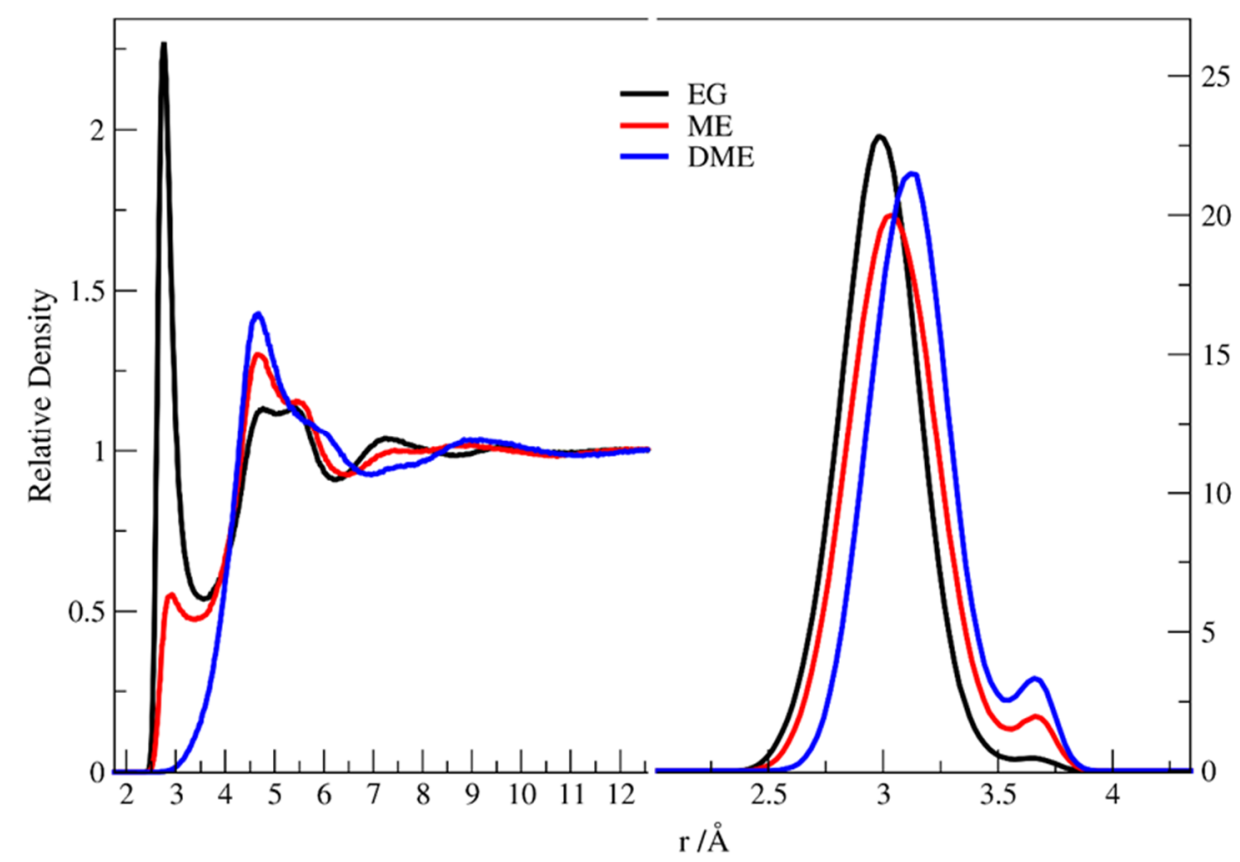

Figure 3. O1-O2 radial distribution function. Intermolecular: left panel; intramolecular: right panel. EG: black, ME: red; DME: blue. 

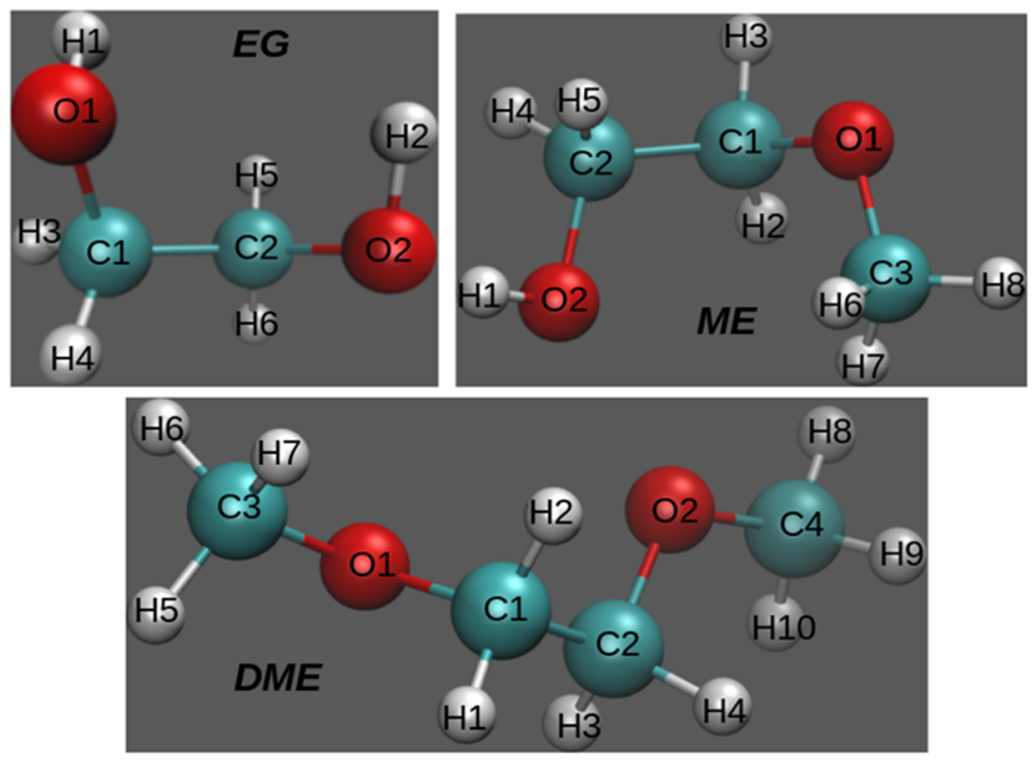

Figure 4. Sketch of the molecules with atom numbering.

In the present study, the predominance of gauche conformers in EG is confirmed by the intramolecular radial distribution functions (Figure 3, right panel) and from dihedral distribution analysis (Figure 5) calculated from simulation trajectory. The former pattern shows a broad peak, centered at $2.96 \AA$; the center of the distribution complies well, considering the large peak width, with the O1-O2 distance of a hypothetical gauche structure [44] having the following bond lengths: $\mathrm{r}(\mathrm{C} 1-\mathrm{C} 2)=1.54 \AA, \mathrm{r}(\mathrm{C} 1-\mathrm{O} 1 / \mathrm{C} 2-\mathrm{O} 2)=1.43 \AA, \mathrm{r}(\mathrm{C}-\mathrm{H})=1.09 \AA, \mathrm{r}(\mathrm{O}-\mathrm{H})=0.97 \AA$, tetrahedral bond angles $\left(\varphi=109^{\circ} 28^{\prime}\right)$ and $60^{\circ}$ internal rotation (torsion) angle, that corresponds to $2.79(5) \AA$. At larger distances, a faint peak due to the anti conformer can be seen around $3.64 \AA$; the relative population of the two conformations, calculated from the ratio of $\mathrm{g}(\mathrm{r})$ 's integrals, is 99:1, pointing out that, in our analysis, almost all EG adopts the gauche form. In ME and DME, the first peak is still largely predominant, but it falls at progressively larger distances. A further proof of such behavior can be found in the dihedral distribution functions, that are shown in Figure 5, It can be seen that in EG two almost equally tall peaks are found at -69 and +68 degrees, while in ME they fall at $-73 /+75$ degrees and at $-81 /+80$ degrees in $\mathrm{DME}$, in agreement with the increases steric hindrance of the alkoxy groups compared to $\mathrm{OH}$. In parallel to the peak shift, the relative population decreases to 95:5 (ME) and 92:8 (DME). Regarding the angular features of the intramolecular hydrogen bond, we calculated the combined distribution function map $(\mathrm{H} 1-\mathrm{O} 2$ radial distribution $+\mathrm{O} 1-\mathrm{H} 1-\mathrm{O} 2$ angular distribution), that is shown in Figure 6 . In the picture, the combined histogram count of the two distributions is reported as contour lines, and clearly points out the existence of two maxima: the taller peak (magenta) corresponds to the distance range 2.75-3.25 A coupled to the angular range 161-163.5 degrees, while the lower one (orange) corresponds to the ranges 3.75-4 $\AA$ and 168.5-174 degrees. This result, although it evidences again the tendency of the molecule to adopt a folded conformation, cannot account clearly for the existence of a hydrogen bond, at least according to the most "canonical" definition, since the interaction distance is rather too large and the angle somewhat too far from linearity. Nonetheless, it should be considered that the simulation was carried out within the framework of the simplest classical force-field approach, where the charge distribution is modeled through atom-centered point charges, thus enforcing the spherical symmetry of the environment, with consequent lack of the directionality in the $\mathrm{O}-\mathrm{H}-\mathrm{O}$ interaction and the maximum filling of the space. The analogous calculation for ME yields a similar picture (see Supplementary Materials Figure S1), but the second peak is a little fainter, probably in line with the increased steric hindrance imposed by the $\mathrm{OCH}_{3}$ group. 


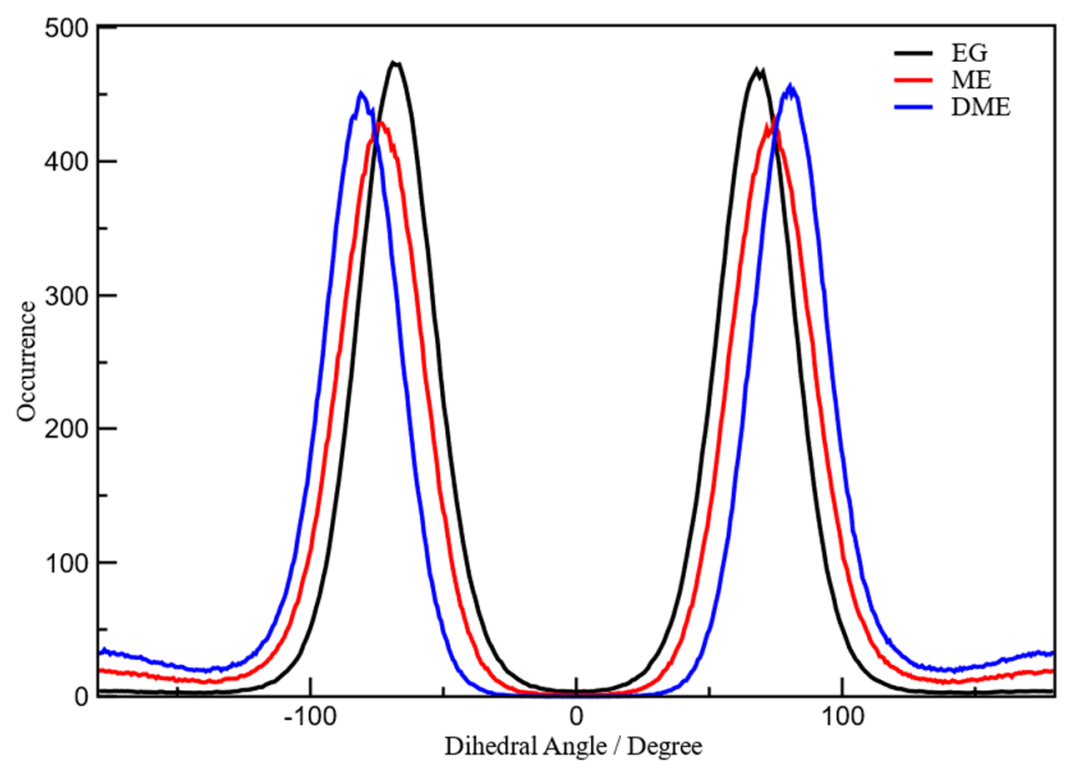

Figure 5. O1-C1-C2-O2 dihedral distribution function.

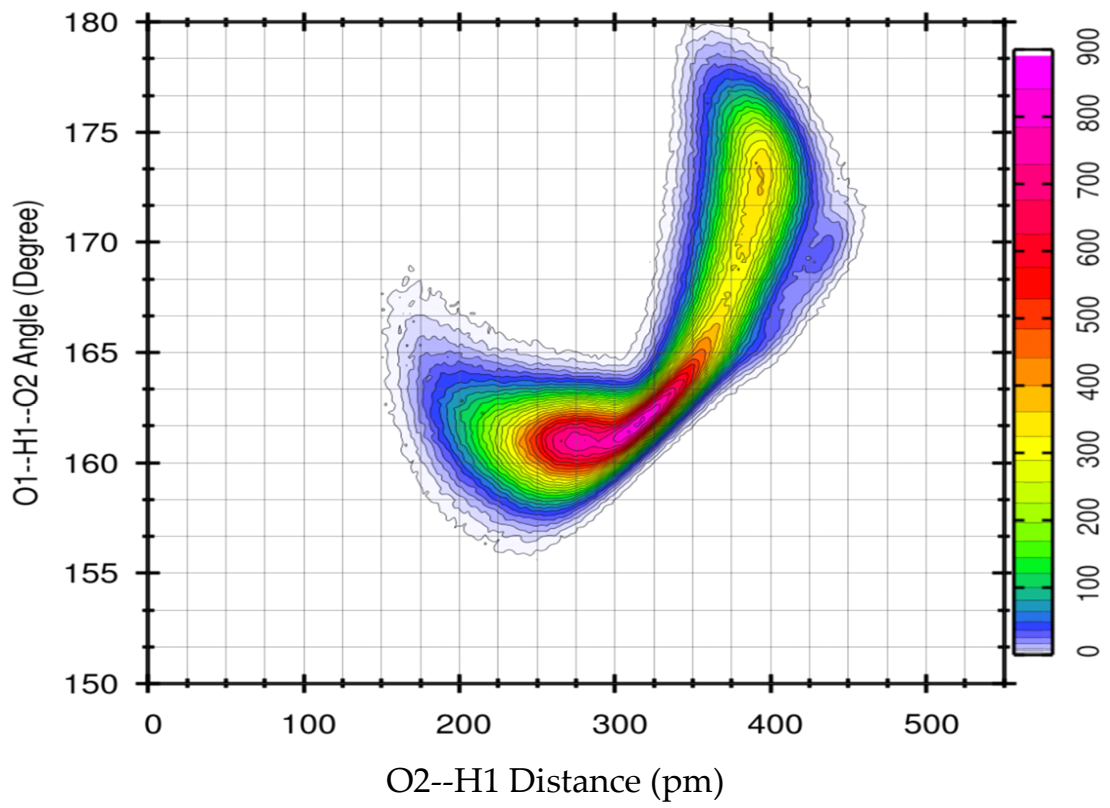

Figure 6. EG: Combined radial and angular distribution function for intramolecular H-bond.

The analysis of the intermolecular function calculated from the molecular dynamics trajectory, validated by X-ray patterns, reveals that a strong intermolecular correlation between oxygen atoms, centered around the peak falling at $2.76 \AA$, is found in EG, indicating the establishment of a hydrogen-bond network in the system quite similar to that observed in liquid water [50]. Noteworthily, the total coordination number, calculated as the sum of the intermolecular radial distribution functions integrals is 3.84. This value is remarkably high, and complies with the view of an extended hydrogen-bond network, though it is significantly lower than water, where experiments point to a total value of 4.7 [51] but larger than liquid methanol (total coordination around 2) [52]. A picture of the intermolecular interactions established in liquid EG can be seen in Figure 7, that qualitatively shows a quite large density of $\mathrm{O}(\mathrm{H}) \cdots \mathrm{O}$ interactions, with an almost linear arrangement of the triad (angle range 165-180 degrees in most of the angular distribution - see the combined distribution function in Figure S2). In ME, the first-neighbor oxygen-oxygen peak is still visible, but it falls at 
larger distance $(2.86 \AA)$ and has a much smaller total integral (O2-O2 1.44, O1-O2 0.41, total 1.85), a not-unexpected issue considering that only one $\mathrm{OH}$ fragment, capable of acting as both $\mathrm{H}$-bond donor and acceptor, is present $\left(\mathrm{O} 2\right.$, see Figure 4), differently from $\mathrm{OCH}_{3}$ group (acceptor only). In DME, the first neighbor peak falls around $4.7 \AA$, the $\mathrm{O}$ atoms lose their donor ability and the O-O correlation is mediated by the interaction between the surrounding methyl groups (see Figure 8).

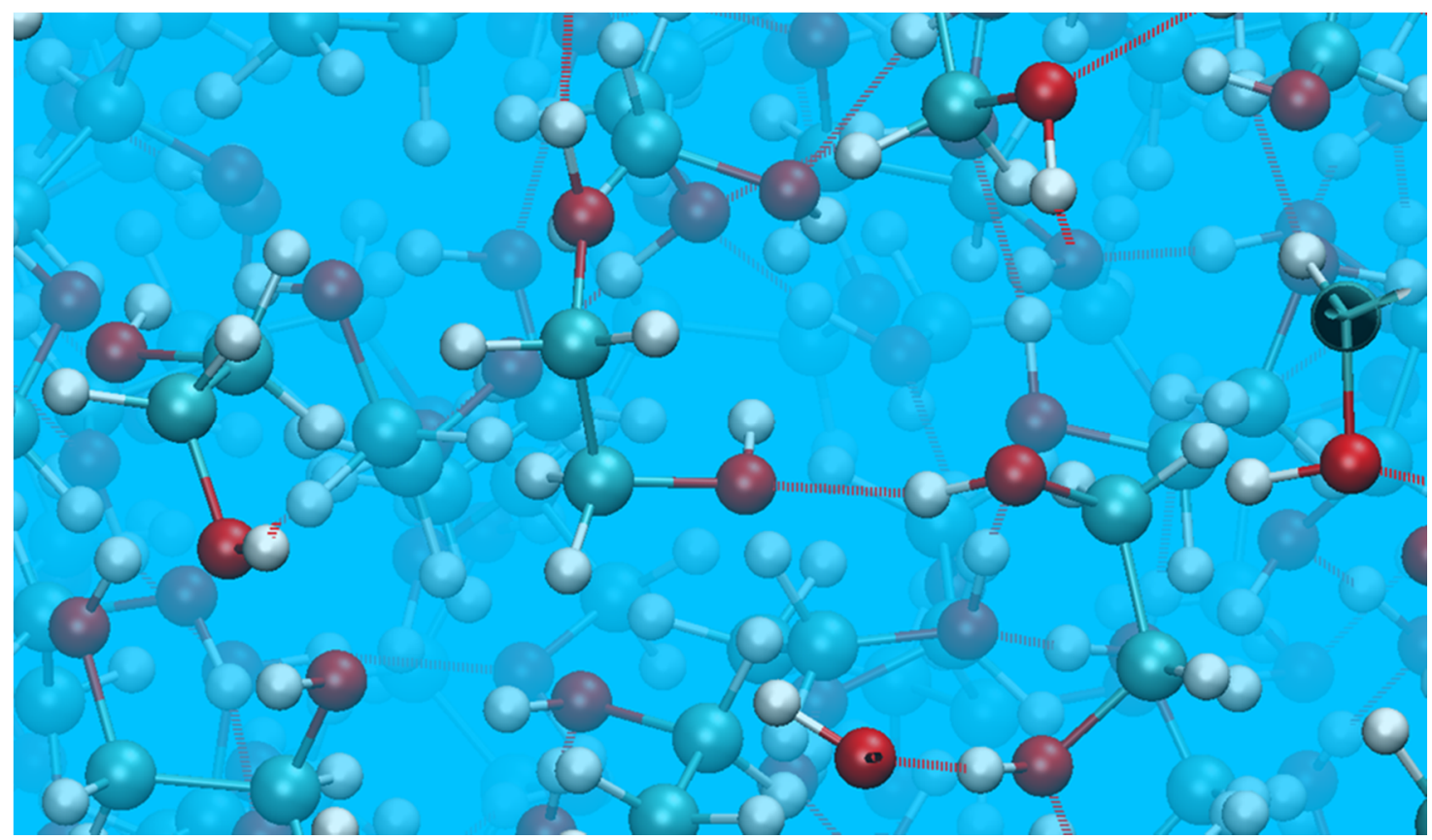

Figure 7. Snapshot of EG MD trajectory, with intermolecular hydrogen bonds interactions highlighted (dashed). The average $\mathrm{O}(\mathrm{H}) \cdots \mathrm{O}$ distance is $2.76 \AA$.

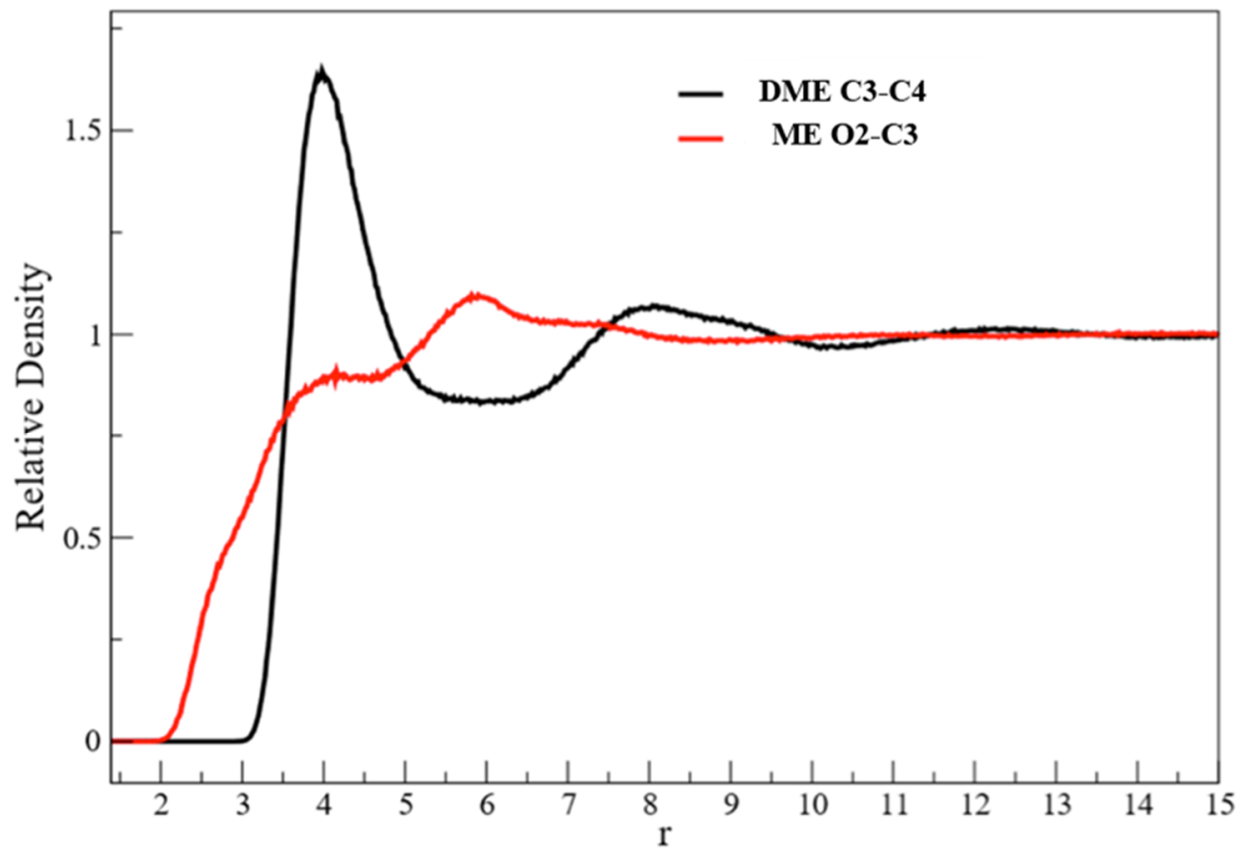

Figure 8. ME and DME hydrogen-methyl and methyl-methyl distribution function. 


\subsection{Raman Study}

\subsubsection{EG}

Further light on the issue of intramolecular hydrogen bonding of liquid ethylene glycol (EG) could be shed from the analysis of its micro-Raman spectrum that was recorded at $22{ }^{\circ} \mathrm{C}$ (room temperature) and is reported in Figure 9.

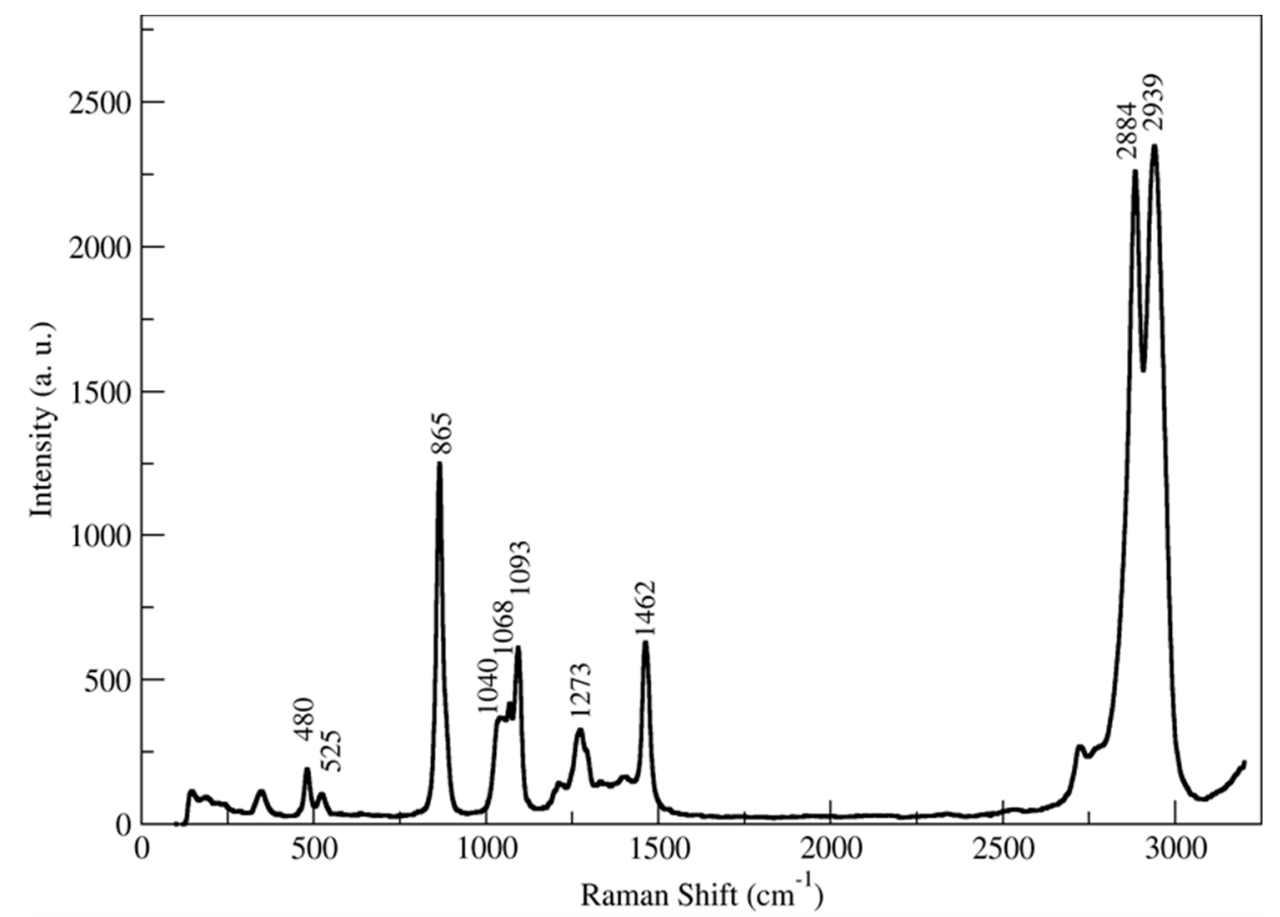

Figure 9. Raman spectrum of liquid ethylene glycol acquired at room temperature $\left(22^{\circ} \mathrm{C}\right)$.

The observed spectrum can be divided into four frequency regions, with assignments largely based on previous studies [44-48]:

1. 400-600 $\mathrm{cm}^{-1}$ : This first region is relevant in order to figure out the presence of rotational isomerism of ethylene glycol in the liquid state. In fact, as well known, in this region two main peaks are present, the $525 \mathrm{~cm}^{-1}$ Raman vibration and the $480 \mathrm{~cm}^{-1}$ band, which are assigned to the antisymmetric mode of the gauche conformer and to the symmetric (Ag) $\mathrm{C}-\mathrm{C}-\mathrm{O}$ bending mode of the anti conformer respectively [45,47].

2. $800-1100 \mathrm{~cm}^{-1}$ : The Raman spectrum of liquid ethylene glycol exhibits a very intense polarized line at about $865 \mathrm{~cm}^{-1}$ due to the $\mathrm{C}-\mathrm{C}$ stretch mode. The region between 1000 and 1100 displays three overlapping bands at 1040, 1068 and $1093 \mathrm{~cm}^{-1}$. the first and third Raman bands are assigned to the stretching modes of the gauche isomer, and the second band to the anti $\mathrm{C}-\mathrm{O}$ stretch (Ag) mode [45].

3. $1400-1500 \mathrm{~cm}^{-1}$ : The vibration located at $1462 \mathrm{~cm}^{-1}$ is unambiguously assigned to the $\mathrm{CH}_{2}$ scissoring vibration [53].

4. 1500-3000 $\mathrm{cm}^{-1}$ : Dominated by the very intense Raman bands at 2884 and $2939 \mathrm{~cm}^{-1}$ corresponding to the stretching mode of $\mathrm{CH}_{2}$ groups.

As anticipated in point (a) above, the two characteristic Raman lines recorded at $480 \mathrm{~cm}^{-1}$ and at $525 \mathrm{~cm}^{-1}$ are originated by the two distinct anti and gauche conformers, and for this reason the variation of their intensity with temperature can be used to predict the relative stability of these two forms, at least qualitatively. Actually, when well defined lines (or group of lines), which can be unambiguously 
attributed to different structures are available in the spectrum, the relative population of two forms $\left(\mathrm{r}_{1,2}\right)$ can be predicted, considering that this quantity follows the Boltzmann law, and ultimately the Van't Hoff equation:

$$
\ln \left(r_{12}\right)=-\frac{\Delta \mathrm{H}_{1,2}}{\mathrm{RT}}+\frac{\Delta \mathrm{S}_{1,2}}{\mathrm{R}}
$$

where $\Delta \mathrm{H}_{1,2}$ and $\Delta \mathrm{S}_{1,2}$ are, respectively, the enthalpy and entropy differences between the two conformers. [see, for instance, [54]). In EG Raman spectrum, as showed in Figure 10, the intensity of the line at $480 \mathrm{~cm}^{-1}$ related to anti configuration has been found to increase when the temperature is raised, while, on the other hand, the $525 \mathrm{~cm}^{-1}$ Raman band, ascribed to the gauche form, exhibits an opposite behavior. This observation confirms that both gauche and anti isomers are present in the liquid state, and that the former group of conformers, stabilized by intramolecular hydrogen bonds of some kind, are made less stable by a temperature increase (as any endothermic process), which, in turn, enhances the population of anti conformers compared to gauche ones.

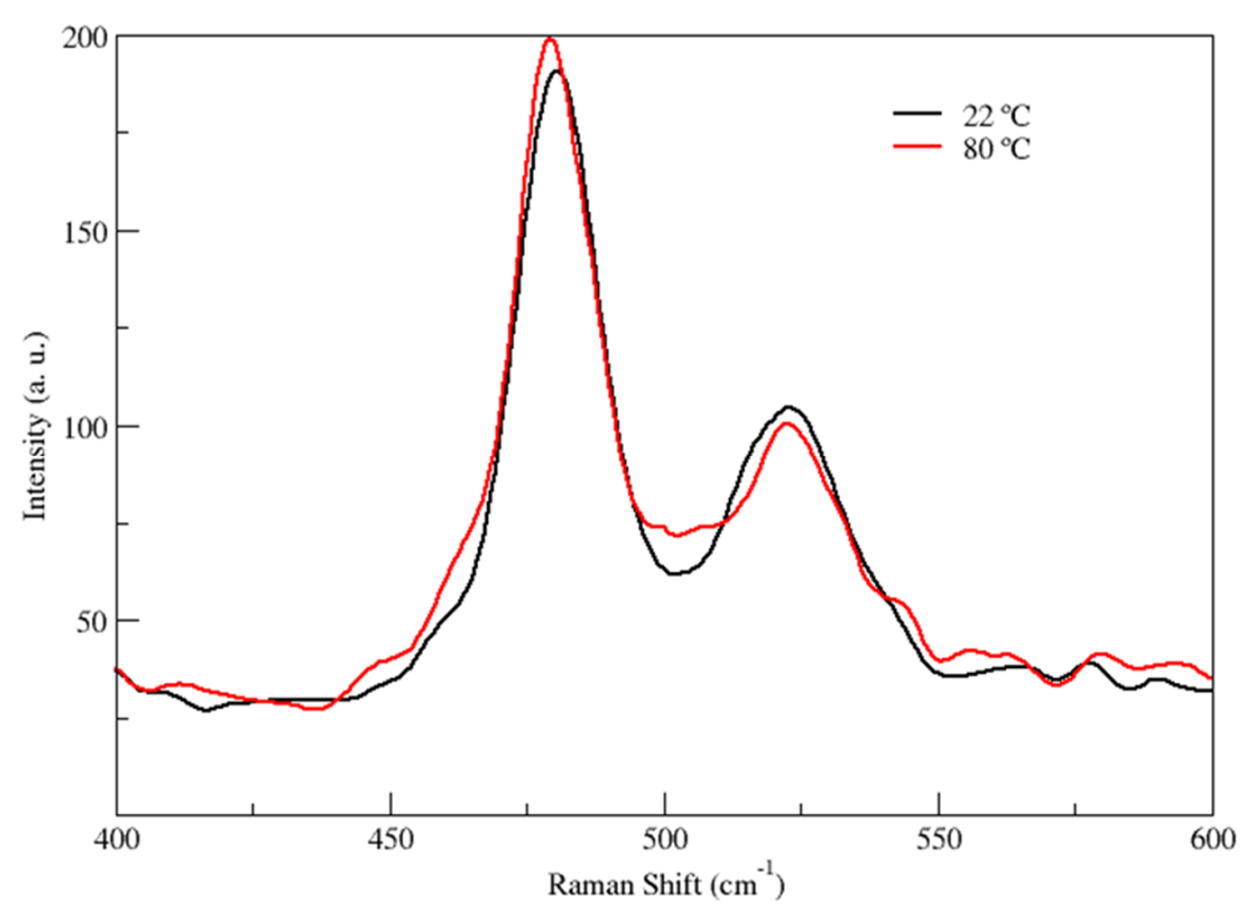

Figure 10. Temperature dependence of Raman intensities at 480 and $525 \mathrm{~cm}^{-1}$ of EG.

\subsection{2. $\mathrm{ME}$}

The Raman spectra of 2-methoxyethan-1-ol acquired at room temperature $\left(\mathrm{T}=22^{\circ} \mathrm{C}\right)$ is shown in Figure 11. As widely discussed in literature [55] the most stable tgg' conformer of 2-methoxyethanol corresponds to the highest monomer population with a population of ca. $92 \%$ at room temperature [56] in optimal agreement with the X-ray data discussed above. Thus, it is expected that the larger contribution to the observed Raman bands in the registered spectra will come from this conformer.

The Raman spectrum suggests three spectral regions:

- The region below the $800 \mathrm{~cm}^{-1}$ which includes different bending and torsional modes;

- The $800-1500 \mathrm{~cm}^{-1}$ region, which includes the $\mathrm{CH}_{3}, \mathrm{CH}_{2}$ and $\mathrm{COH}$ bending vibrations and the $\mathrm{CC}$ and $\mathrm{CO}$ stretching modes.

- The $2700-3200 \mathrm{~cm}^{-1}$ region, the $\mathrm{O}-\mathrm{H}$ and $\mathrm{C}-\mathrm{H}$ stretching vibrations.

It is well known the existence of dimeric species in neat 2-methoxyethanol liquid, with intra- and intermolecular hydrogen bonds. 


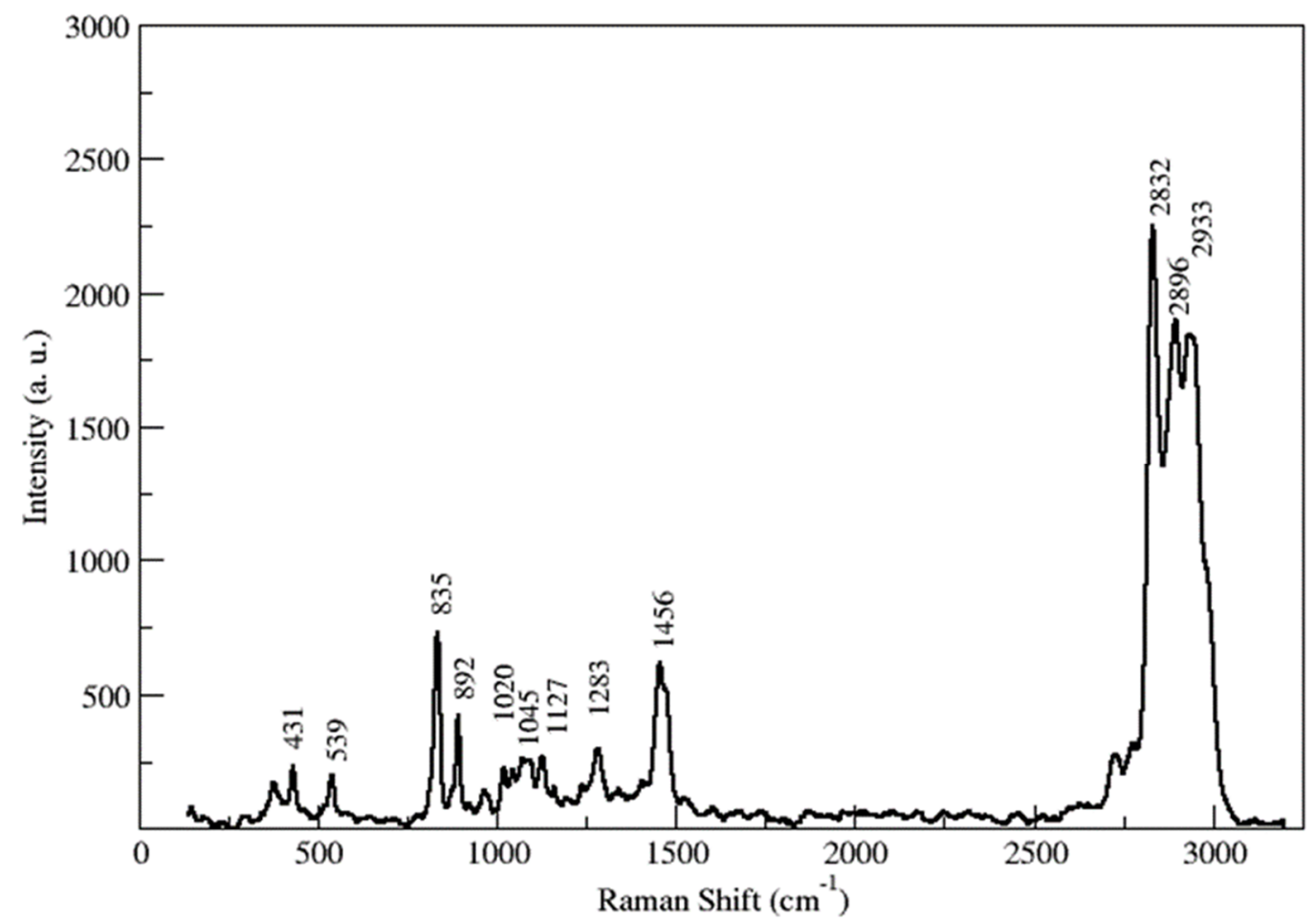

Figure 11. Raman spectrum of room temperature 2-methoxyethan-1-ol.

\section{Conclusions}

Throughout this paper, we investigated the structural and spectroscopic properties of three organic liquids with oxygen substituents: the forefather of glycols (ethane-1,2-diol-ethylene glycol) and the two simplest mono and di-alkyl derivatives, 2-methoxyethan-1-ol and 1,2-dimethoxy ethane. While the information for the last two liquid systems is still rather scarce, ethane-1,2-diol has already been extensively studied in the past. Yet, to get a complete picture and assess similarities and differences, the molecular arrangement of ethane-1,2-diol was reappraised as well. With this aim, the X-ray diffraction spectra of the three systems were measured with an energy-dispersive instrument, and the patterns obtained were optimally reproduced by those obtained from molecular dynamics simulations. The analysis of the radial and dihedral distribution functions sampled in MD trajectory, confirms the conformational landscape already observed for ethane-1,2-diol and points out the large predominance of gauche conformations, that allow the establishment of intramolecular H-bond interactions, while this feature is largely decreased in 2-methoxyethan-1-ol where one hydroxy group is replaced by an alkoxy one. Looking at the cohesive interactions between molecules, the diffraction results reveal the existence of an extended hydrogen-bond network, which is signaled by intense oxygen-oxygen radial distribution functions in ethane-1,2-diol, where every molecule is surrounded by other 3.84 on average, and, to a lesser extent, in 2-methoxyethan-1-ol. In 1,2-dimethoxyethane, instead, the main intermolecular correlation is the hydrophobic interaction between the two methyl groups. The conformational landscape of ethane-1,2-diol and 2-methoxyethan-1-ol was further assessed by a micro-Raman study in the liquid phase. The study unambiguously shows that in the former compound the gauche form is largely predominant, and decreases its population, partially transforming into the less stable anti form, when the temperature is increased. In 2-methoxyethan-1-ol, tgg' conformer is the major component.

Supplementary Materials: The following are available online at http://www.mdpi.com/2073-4352/10/11/1011/s1, Figure S1: ME: Combined radial and angular distribution function for intramolecular H-bond, Figure S2: ME: Combined radial and angular distribution function for intermolecular H-bond. 
Author Contributions: Conceptualization, M.C. and L.G.; methodology, L.G., M.C., A.A. and S.P.; software, L.G.; validation, L.G., M.C. and A.A.; formal analysis, L.G. and M.C.; investigation, L.G., A.A. and S.P.; resources, P.T. and M.C.; data curation, L.G. and A.A.; writing-original draft preparation, L.G., M.C., A.A. and S.P.; writing-review and editing, L.G.; visualization, M.C.; supervision, M.C.; project administration, M.C.; funding acquisition, P.T. All authors have read and agreed to the published version of the manuscript.

Funding: This research received no external funding.

Acknowledgments: L.G. and M.C. acknowledge assistance in the X-ray measurements by Ruggero Caminiti.

Conflicts of Interest: The authors declare no conflict of interest.

\section{References}

1. Diaz, A.; Katsarava, R.; Puiggali, J. Synthesis, Properties and Applications of Biodegradable Polymers Derived from Diols and Dicarboxylic Acids: From Polyesters to Poly(ester amide)s. Int. J. Mol. Sci. 2014, 15, 7064-7123. [CrossRef] [PubMed]

2. Turecek, P.; Bossard, M.; Schoetens, F.; Ivens, I. PEGylation of Biopharmaceuticals: A Review of Chemistry and Nonclinical Safety Information of Approved Drugs. J. Pharm. Sci 2016, 105, 460-475. [CrossRef] [PubMed]

3. Fettaka, H.; Lefebvre, M. Ethylene Glycol Dinitrate (EGDN): From Commercial Precursors, Physicochemical and Detonation Characterization. Cent. Eur. J. Energ. Mat. 2015, 12, 287-305.

4. Zagrebin, P.; Buchner, R.; Nazmutdinov, R.; Tsirlina, G. Dynamic Solvent Effects in Electrochemical Kinetics: Indications for a Switch of the Relevant Solvent Mode. J. Phys. Chem. B 2010, 114, 311-320. [CrossRef] [PubMed]

5. Ismailova, O.; Berezin, A.S.; Probst, M.; Nazmutdinov, R.R. Interfacial Bond-Breaking Electron Transfer in Mixed Water-Ethylene Glycol Solutions: Reorganization Energy and Interplay between Different Solvent Modes. J. Phys. Chem. B 2013, 117, 8793-8801. [CrossRef]

6. Ibrahim, R.; Hayyan, M.; AlSaadi, M.; Ibrahim, S.; Hayyan, A.; Hashim, M. Physical properties of ethylene glycol-based deep eutectic solvents. J. Mol. Liq. 2019, 276, 794-800. [CrossRef]

7. Saiz, L.; Padro, J.; Guardia, E. Structure of liquid ethylene glycol: A molecular dynamics simulation study with different force fields. J. Chem. Phys. 2001, 114, 3187-3199. [CrossRef]

8. Zhang, N.; Li, M.; Zhang, F. Structure and dynamics properties of liquid ethylene glycol from molecular dynamics simulations. Chem. Phys. Lett. 2019, 718, 12-21. [CrossRef]

9. Kaur, S.; Shobhna; Kashyap, H. Insights Gained from Refined Force-Field for Pure and Aqueous Ethylene Glycol through Molecular Dynamics Simulations. J. Phys. Chem. B 2019, 123, 6543-6553. [CrossRef] [PubMed]

10. Kazerouni, M.; Hedberg, L.; Hedberg, K. Conformational analysis.21. Ethane-1,2-diol. An electron-diffraction investigation, augmented by rotational constants and ab initio calculations, of the molecular structure, conformational composition, SQM vibrational force field, and anti-gauche energy difference with implications for internal hydrogen bonding. J. Am. Chem. Soc. 1997, 119, 8324-8331.

11. Christen, D.; Coudert, L.H.; Larsson, J.A.; Cremer, D. The Rotational-Torsional Spectrum of the g' $\mathrm{Gg}$ Conformer of Ethylene Glycol: Elucidation of an Unusual Tunneling Path. J. Mol. Spectrosc. 2001, 205, 185-196. [CrossRef]

12. Park, C.G.; Tasumi, M. Reinvestigation of Infrared-Induced Conformational Isomerizations of 1,2-Ethanediol in Low-Temperature Ar Matrices and Reverse Reaction in the Dark. J. Phys. Chem. 1991, 95, 2757-2762. [CrossRef]

13. Frei, H.; Ha, T.-K.; Meyer, R.; Gūnthard, H.H. Ethylene glycol: Infrared spectra, AB initio calculations, vibrational analysis and conformations of 5 matrix isolated isotopic modifications. Chem. Phys. 1977, 25, 271-298. [CrossRef]

14. Bakó, I.; Grósz, T.; Pálinkás, G.; Bellissent-Funel, M.C. Ethylene glycol dimers in the liquid phase: A study by x-ray and neutron diffraction. J. Chem. Phys. 2003, 118, 3215-3221. [CrossRef]

15. Fortes, A.D.; Suard, E. Crystal structures of ethylene glycol and ethylene glycol monohydrate. J. Chem. Phys. 2011, 135, 234501. [CrossRef]

16. Chen, Y.; Ozaki, Y.; Czarnecki, M.A. Molecular structure and hydrogen bonding in pure liquid ethylene glycol and ethylene glycol-water mixtures studied using NIR spectroscopy. Phys. Chem. Chem. Phys. 2013, 15, 18694-18701. [CrossRef] 
17. Rodnikova, M.N.; Chumaevskii, N.A.; Troitskii, V.M.; Kayumova, D.B. Structure of liquid ethylene glycol. Russ. J. Phys. Chem. 2006, 80, 826-830. [CrossRef]

18. Sengwa, R.; Madhvi, A. A comparative study of non-polar solvents effect on dielectric relaxation and dipole moment of binary mixtures of mono alkyl ethers of ethylene glycol and of diethylene glycol with ethyl alcohol. J. Mol. Liq. 2006, 123, 92-104. [CrossRef]

19. Miller, R.R.; Ayres, J.A.; Calhoun, L.L.; Young, J.T.; McKenna, M.J. Comparative Short-Term Inhalation Toxicity of Ethylene Glycol Monomethyl Ether and Propylene Glycol Monomethyl Ether in Rats and Mice. Toxicol. Appl. Pharmacol. 1981, 61, 368-377. [CrossRef]

20. Caminiti, R.; Albertini, V.R. The kinetics of phase transitions observed by energy-dispersive X-ray diffraction. Int. Rev. Phys. Chem. 1999, 18, 263-299. [CrossRef]

21. Gontrani, L.; Ballirano, P.; Leonelli, F.; Caminiti, R. X-Ray Diffraction Studies of Ionic Liquids: From Spectra to Structure and Back. In The Structure of Ionic Liquids; Caminiti, R., Gontrani, L., Eds.; Springer International Publishing: Cham, Switzerland, 2014; pp. 1-37.

22. Caminiti, R.; Carbone, M.; Mancini, G.; Sadun, C. Study of cetyltrialkylammonium bromide and tribromide salts in the solid phase. J. Mater. Chem. 1997, 7, 1331-1337. [CrossRef]

23. Carbone, M.; Caminiti, R.; Sadun, C. Structural study by energy dispersive X-ray diffraction of amorphous mixed hydroxycarbonates containing Co, Cu, Zn, Al. J. Mater. Chem. 1996, 6, 1709-1716. [CrossRef]

24. Caminiti, R.; Carbone, M.; Panero, S.; Sadun, C. Conductivity and structure of poly(ethylene glycol) complexes using energy dispersive X-ray diffraction. J. Phys. Chem. B 1999, 103, 10348-10355. [CrossRef]

25. Carbone, M.; Ballirano, P.; Caminiti, R. Kinetics of gypsum dehydration at reduced pressure: An energy dispersive X-ray diffraction study. Eur. J. Miner. 2008, 20, 621-627. [CrossRef]

26. Keen, D.A. A comparison of various commonly used correlation functions for describing total scattering. J. Appl. Crystallogr. 2001, 34, 172-177. [CrossRef]

27. Gontrani, L.; Ramondo, F.; Caminiti, R. Energy dispersive X-ray diffraction and molecular dynamics meet: The structure of liquid pyrrole. Chem. Phys. Lett. 2006, 417, 200-205. [CrossRef]

28. Gontrani, L.; Ramondo, F.; Caracciolo, G.; Caminiti, R. A study of cyclohexane, piperidine and morpholine with X-ray diffraction and molecular simulations. J. Mol. Liq. 2008, 139, 23-28. [CrossRef]

29. Gontrani, L.; Caminiti, R. The structure of liquid N-methyl pyrrolidone probed by X-ray scattering and molecular simulations. J. Chem. Phys. 2012, 136, 074505. [CrossRef]

30. Campetella, M.; Gontrani, L.; Bodo, E.; Ceccacci, F.; Marincola, F.; Caminiti, R. Conformational isomerisms and nano-aggregation in substituted alkylammonium nitrates ionic liquids: An X-ray and computational study of 2-methoxyethylammonium nitrate. J. Chem. Phys. 2013, 138, 184506. [CrossRef]

31. Valentini, F.; Roscioli, D.; Carbone, M.; Conte, V.; Floris, B.; Palleschi, G.; Flammini, R.; Bauer, E.M.; Nasillo, G.; Caponetti, E. Oxidized graphene in ionic liquids for assembling chemically modified electrodes: A structural and electrochemical characterization study. Anal. Chem. 2012, 84, 5823-5831. [CrossRef] [PubMed]

32. Bonomo, M.; Gontrani, L.; Capocefalo, A.; Sarra, A.; Nucara, A.; Carbone, M.; Postorino, P.; Dini, D. A combined electrochemical, infrared and EDXD tool to disclose Deep Eutectic Solvents formation when one precursor is liquid: Glyceline as case study. J. Mol. Liq. 2020, 319, 114292. [CrossRef]

33. Usula, M.; Mocci, F.; Marincola, F.C.; Porcedda, S.; Gontrani, L.; Caminiti, R. The structural organization of $\mathrm{N}$-methyl-2-pyrrolidone + water mixtures: A densitometry, X-ray diffraction, and molecular dynamics study. J. Chem. Phys. 2014, 140, 124503. [CrossRef]

34. Salma, U.; Usula, M.; Caminiti, R.; Gontrani, L.; Plechkova, N.V.; Seddon, K.R. X-ray and molecular dynamics studies of butylammonium butanoate-water binary mixtures. Phys. Chem. Chem. Phys. 2017, 19, 1975-1981. [CrossRef] [PubMed]

35. Caminiti, R.; Carbone, M.; Sadun, C. Palladium (II) and platinum (II) aqueous solutions. Evidence for the solvation of the $\left[\mathrm{PdCl}_{4}\right]^{2-}$ and $\left[\mathrm{PtCl}_{4}\right]^{2-}$ ions. J. Mol. Liq. 1998, 75, 149-158. [CrossRef]

36. Gontrani, L.; Caminiti, R.; Bencivenni, L.; Sadun, C. Molecular aggregation phenomena in solution: An energy dispersive X-ray diffraction study of concentrated imidazole water solutions. Chem. Phys. Lett. 1999, 301, 131-137. [CrossRef]

37. Fakharuddin, A.; Seybold, M.; Agresti, A.; Pescetelli, S.; Matteocci, F.; Haider, M.; Birkhold, S.; Hu, H.; Giridharagopal, R.; Sultan, M.; et al. Perovskite-Polymer Blends Influencing Microstructures, Nonradiative Recombination Pathways, and Photovoltaic Performance of Perovskite Solar Cells. ACS Appl. Mater. Interfaces 2018, 10, 42542-42551. [CrossRef] 
38. Yadav, S.K.; Ravishankar, S.; Pescetelli, S.; Agresti, A.; Fabregat-Santiago, F.; Di Carlo, A. Stability of dye-sensitized solar cells under extended thermal stress. Phys. Chem. Chem. Phys. 2017, 19, 22546-22554. [CrossRef] [PubMed]

39. Agresti, A.; Cina, L.; Pescetelli, S.; Taheri, B.; Di Carlo, A. Stability of dye-sensitized solar cell under reverse bias condition: Resonance Raman spectroscopy combined with spectrally resolved analysis by transmittance and efficiency mapping. Vib. Spectrosc. 2016, 84, 106-117. [CrossRef]

40. Case, D.A.; Belfon, K.; Ben-Shalom, I.Y.; Brozell, S.R.; Cerutti, D.S.; Cheatham, T.E., III; Cruzeiro, V.W.D.; Darden, T.A.; Duke, R.E.; Giambasu, G.; et al. AMBER 2020; University of California: San Francisco, CA, USA, 2020.

41. Wang, J.; Wolf, R.M.; Caldwell, J.W.; Kollman, P.A.; Case, D.A. Development and testing of a general AMBER force field. J. Comput. Chem. 2004, 25, 1157-1174. [CrossRef]

42. Martínez, L.; Andrade, R.; Birgin, E.G.; Martínez, J. Packmol: A package for building initial configurations for molecular dynamics simulations. J. Comput. Chem. 2009, 30, 2157-2164. [CrossRef]

43. Brehm, M.; Thomas, M.; Gehrke, S.; Kirchner, B. TRAVIS-A Free Analyzer for Trajectories from Molecular Simulation. J. Chem. Phys. 2020, 152, 164105. [CrossRef]

44. Matsuura, H.; Miyazawa, T. Infrared spectra and molecular vibrations of ethylene glycol and deuterated derivatives. Bull. Chem. Soc. Jpn. 1967, 40, 85-94. [CrossRef]

45. Matsuura, H.; Hiraishi, M.; Miyazawa, T. Raman spectra and energy difference between rotational isomers of ethylene glycol. Spectrochim. Acta Part A 1972, 28, 2299. [CrossRef]

46. Takeuchi, H.; Tasumi, M. Infrared-induced conformational isomerization of ethylene glycol in a low-temperature argon matrix. Chem. Phys. 1983, 77, 21-34. [CrossRef]

47. Schwartz, M. Raman study of the conformational equilibrium of ethylene glycol in dimethyl sulfoxide. Spectrochim. Acta Part A 1977, 33, 1025-1032. [CrossRef]

48. Richardson, J.W.; Pluth, J.J.; Smith, J.V.; Dytrych, W.J.; Bibby, D.M. Conformation of ethylene glycol and phase change in silica sodalite. J. Phys. Chem. 1988, 92, 243-247. [CrossRef]

49. Pachler, K.G.R.; Wessels, P.L. Rotational isomerism: X. A nuclear magnetic resonance study of 2-fluoro-ethanol and ethylene glycol. J. Mol. Struct. 1970, 6, 471-478. [CrossRef]

50. Soper, A.K.; Fernandez-Alonso, F.; Price, D.L. Chapter 3-The Structure of Water and Aqueous Systems. In Experimental Methods in the Physical Sciences; Academic Press: Cambridge, MA, USA, 2017; Volume 49, pp. 135-211.

51. Head-Gordon, T.; Johnson, M.E. Tetrahedral structure or chains for liquid water. Proc. Natl. Acad. Sci. USA 2006, 103, 7973. [CrossRef]

52. Migliorati, V.; D'Angelo, P. Unraveling the perturbation induced by $\mathrm{Zn}^{2+}$ and $\mathrm{Hg}^{2+}$ ions on the hydrogen bond patterns of liquid methanol. Chem. Phys. Lett. 2015, 633, 70-75. [CrossRef]

53. Krischnan, K.; Krisrtnan, R.S. Raman and Infrared Spectra of Ethylene Glycol. Proc. Indian Acad. Sci. 1966, A64, 111-123. [CrossRef]

54. Palumbo, O.; Paolone, A.; Campetella, M.; Ramondo, F.; Cappelluti, F.; Gontrani, L. New insights into chloromethyl-oxirane and chloromethyl-thiirane in liquid and solid phase from low-temperature infrared spectroscopy and ab initio modeling. Spectrochim. Acta, Part 2020, 247, 119061. [CrossRef]

55. Amorim da Costa, A.M.; Duarte, A.S.R.; Amado, A.M. Molecular aggregation in neat 2-methoxyethanol and in 2-methoxyethanol/acrylamide solutions-A study by Raman spectroscopy and ab initio calculations. Vib. Spectrosc. 2006, 42, 302-308. [CrossRef]

56. Gil, F.P.S.C.; Amorim da Costa, A.M.; Teixeira-Dias, J.J.C. Oxygen-by-Sulfur Substitution in $\mathrm{CH}_{3} \mathrm{OCH}_{2} \mathrm{CH}_{2} \mathrm{OH}$ : An Ab Initio Comparative Study of Conformational Effects and Intramolecular Interactions. J. Phys. Chem. 1995, 99, 16586-16589. [CrossRef]

Publisher's Note: MDPI stays neutral with regard to jurisdictional claims in published maps and institutional affiliations. 